\title{
Prednisolone and Mustine in Prevention of Tumour Swelling during Pulmonary Irradiation
}

\author{
S. J. CAMERON, I. W. B. GRANT, J. G. PEARSON, C. MARQUES
}

British Medical fournal, 1972, 1, 535-537

\section{Summary}

Ventilatory function declines during the early stages of irradiation for bronchial carcinoma. This decline is potentially dangerous if the tumour narrows the trachea or both main bronchi. The protective effect of preliminary treatment with prednisolone or mustine before irradiation was studied in 88 patients by serial estimations of forced expiratory volume and forced vital capacity. Twenty-three patients received prednisolone by mouth, 24 had mustine intravenously, and 41 had no preliminary treatment. Both prednisolone and mustine prevented a significant decline in ventilatory function due to tumour swelling, prednisolone being marginally superior. It is concluded that all patients at risk should be treated with oral prednisolone, $20 \mathrm{mg}$ daily, for one day before and two days after the first fraction of irradiation.

\section{Introduction}

For some years we have had the impression that patients with tumours extensively involving the trachea and major bronchi are liable to develop severe respiratory distress, or even to die from asphyxia, during the early stages of a course of treatment with deep $x$ rays. This phenomenon was recently investigated in a prospective study of 42 patients by means of serial estimations of ventilatory function during irradiation for bronchial carcinoma (Cameron et al., 1969).

All patients with tumour or metastatic lymph nodes involving the trachea, main carina, or both main bronchi showed a significant decline in the forced expiratory volume in one second $\left(F E V_{1}\right)$ after two to four treatment fractions. This decline was temporary, and had been reversed by the end of the first week of therapy, presumably as a result of tumour shrinkage caused by cell death as irradiation continued. A similar but less pronounced decline was observed in most patients with tumours involving a main or lobar bronchus. It was suggested that the initial reduction in $\mathrm{FEV}_{1}$ was due to intracellular and extracellular oedema with resultant tumour swelling. Although temporary, this tumour swelling in the early stages of irradiation was considered to be potentially dangerous, particularly when the tumour involved the tracheal bifurcation or a main or lobar bronchus in patients whose pulmonary function was already seriously compromised by chronic bronchitis and emphysema. It was postulated that preliminary treatment with either corticosteroids or mustine hydrochloride might prevent tumour swelling and consequent aggravation of airway obstruction. We now report a new study designed to test this hypothesis.

\footnotetext{
Respiratory Diseases Unit, Northern General Hospital, Edinburgh EH5 2DQ, and Department of Respiratory Diseases, University of Edinburgh

S. J. CAMERON, M.R.C.P., Senior Registrar

I. W. B. GRANT, F.R.C.P., Consultant Physician

Radiotherapy Unit, Western General Hospital, Edinburgh 4

J. G. PEARSON, F.R.C.S., F.F.R., Consultant Radiotherapist (Present appointment: Director of Radiotherapy, Cross Cancer Institute, Edmonton, Alberta, Canada)

Department of Social Medicine, University of Edinburgh C. MARQUES, Research Assistant
}

\section{Case Selection}

All the 88 patients included in the study had partial obstruction of a lobar or larger bronchus. They received either radical irradiation with 5,000 rads given in 20 fractions over four weeks or palliative irradiation with 2,000 rads given in six fractions in one week. Forty-seven patients were divided at random into two groups for preliminary treatment with mustine hydrochloride or prednisolone, and 41 patients included in the previous study (Cameron et al., 1969) formed the third (control) group.

The Mustine Group (M) consisted of 24 patients who received an intravenous infusion of mustine hydrochloride $(0.4 \mathrm{mg} /$ $\mathrm{kg}$ body weight) 48 hours before the start of irradiation. The Prednisolone Group $(P)$ consisted of 23 patients who were treated with prednisolone in a dose of $20 \mathrm{mg}$ /day by mouth for 24 hours before and 48 hours after the start of irradiation. The Control Group $(C)$ consisted of 41 patients included in our previous report who received no preliminary drug treatment before irradiation.

The patients in each group were divided into two subgroups on the basis of the bronchoscopic findings. Subgroup 1 consisted of patients in whom the tumour involved the trachea or both main bronchi and Subgroup 2 of patients in whom the tumour involved a main or lobar bronchus.

All patients were selected and classified in the same way as those reported in the earlier study. The numbers in the various groups and subgroups and their pretreatment status are shown in Table I.

TABLE I-Pretreatment Status of 47 Patients Studied, with Details of 41 Control Patients

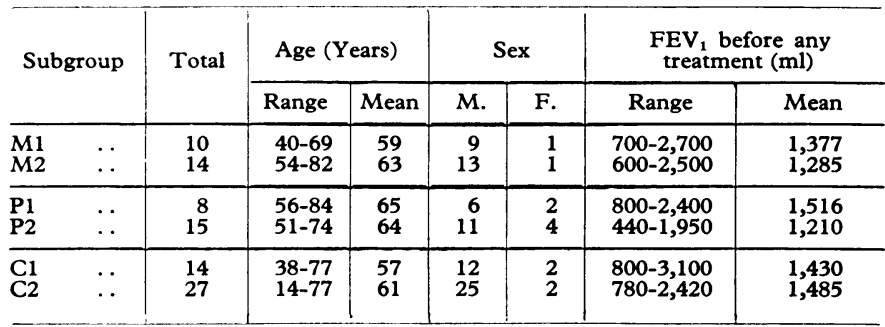

\section{Method of Investigation}

During the first three days in hospital, before treatment was started, five separate measurements (each the highest of three recordings) were made of forced expiratory volume in one second $\left(\mathrm{FEV}_{1}\right)$ and forced vital capacity (FVC) with a Vitalograph dry spirometer. The same measurements were made twice daily (at 9 a.m. and 6 p.m.) after the intravenous infusion of mustine hydrochloride, or following the start of oral treatment with prednisolone. These measurements were then repeated twice daily during the first seven days of irradiation treatment.

\section{Results}

Control Group (C1/C2).-The results in this group are those reported in our previous paper (Cameron et al., 1969). In Subgroup $\mathrm{C} 1$ there was a significant fall in $\mathrm{FEV}_{1}$ in all 14 patients during the first three days of irradiation, followed by a steady 
TABLE II-Forced Expiratory Volume and Indices of Decline before Treatment with Mustine or Prednisolone and during Subsequent Irradiation

\begin{tabular}{|c|c|c|c|c|c|c|c|c|c|c|c|}
\hline \multirow{2}{*}{\multicolumn{3}{|c|}{ Subgroup }} & \multicolumn{4}{|c|}{$\mathrm{FEV}_{1}$ before Irradiation } & \multicolumn{5}{|c|}{$\mathrm{FEV}_{1}$ during 1st Week of Irradiation } \\
\hline & & & \multicolumn{2}{|c|}{ Before Drug Treatment } & \multicolumn{2}{|c|}{ After Drug Treatment } & $\begin{array}{c}\text { Mean of } \\
\text { Lowest } 2 \text { FEV } \\
\text { Readings }\end{array}$ & \multicolumn{2}{|c|}{ Index of Decline } & \multicolumn{2}{|c|}{ Index of Decline } \\
\hline $\begin{array}{l}\mathrm{M1} \\
\mathrm{M2}\end{array}$ & $\therefore$ & $\therefore$ & $\begin{array}{l}700 / 2,700 \\
600 / 2,500\end{array}$ & $\begin{array}{l}1,377 \\
1,285\end{array}$ & $\begin{array}{l}630 / 2,510 \\
560 / 2,400\end{array}$ & $\begin{array}{l}1,352 \\
1,220\end{array}$ & $\begin{array}{l}1,210 \\
1,187\end{array}$ & $\begin{array}{r}-0.34 / 4 \cdot 23 \\
0.50 / 3.47\end{array}$ & $\begin{array}{l}1.99 \\
1.83\end{array}$ & $\begin{array}{l}-0.52 / 4.73 \\
-2 \cdot 44 / 3.47\end{array}$ & $\begin{array}{l}1.85 \\
1.00^{*}\end{array}$ \\
\hline $\begin{array}{l}\text { P1 } \\
\text { P2 }\end{array}$ &. & $\therefore$ & $\begin{array}{l}800 / 2,400 \\
440 / 1,950 \\
\end{array}$ & $\begin{array}{l}1,516 \\
1,210 \\
\end{array}$ & $\begin{array}{l}900 / 2,450 \\
450 / 1,900\end{array}$ & $\begin{array}{l}1,605 \\
1,217\end{array}$ & $\begin{array}{l}1,486 \\
1,140\end{array}$ & $\begin{array}{r}-0.79 / 2 \cdot 23 \\
0.08 / 3.73\end{array}$ & $\begin{array}{l}0.92 \\
1.49 \\
\end{array}$ & $\begin{array}{l}-0.57 / 2.02 \\
-0.50 / 3.73\end{array}$ & $\begin{array}{l}0.77 \\
1.35\end{array}$ \\
\hline
\end{tabular}

*The low value of 1.00 is due to two patients in whom the $\mathrm{FEV}_{1}$ declined sharply after mustine infusion before irradiation. If these patients are excluded the average $\mathrm{I}_{3}$ for the $12 \mathrm{M} 2$ patients is 1.48 .

improvement. In Subgroup C2 22 of the 27 patients showed a significant reduction in $\mathrm{FEV}_{1}$ during the first four days of irradiation. The decline in $\mathrm{FEV}_{1}$ in both subgroups was significantly greater $(P<0.01)$ than that observed in patients who received irradiation to peripheral bronchial tumours or to extrathoracic tumours. The average and range of $\mathrm{FEV}_{1}$ before irradiation, with the mean of the lowest two readings during the first week of irradiation, are shown in Table II.

Mustine Group (M1/M2).- The average and range of the five pretreatment readings of $\mathrm{FEV}_{1}$ and of the four readings after mustine, and the mean of the lowest two recordings of FEV during the first week of irradiation, are shown in Table II. Intravenous infusion of mustine hydrochloride two days before the first fraction of irradiation was followed by a slight fall in FEV $_{1}$ in some patients, but this was not pronounced in any individual patient. There was no significant decline in serial readings during the first week of irradiation in any of the 10 patients with central tumours (Subgroup M1) or of the 14 patients with more peripheral lesions (Subgroup M2).

Prednisolone Group (P1/P2).-The results for this group are also shown in Table II. There was no early decline in $\mathrm{FEV}_{1}$ in eight patients with central tumours (Subgroup P1) or in 15 patients with more peripheral tumours (Subgroup P2). Indeed, preliminary treatment with prednisolone was associated with a slight but significant improvement in $\mathrm{FEV}_{1}$ over the baseline readings. Subsequent irradiation did not cause a significant fall in $\mathrm{FEV}_{1}$ in any patient, and in most patients the preirradiation improvement was maintained.

\section{Notes on Statistical Analysis}

Effect of Preliminary Drug Treatment Itself.-The average of the five readings of $\mathrm{FEV}_{1}$ for each patient after admission was compared with the average $\mathrm{FEV}_{1}$ during drug treatment. The statistical analysis of these data (Table III) confirmed that preliminary treatment with prednisolone in patients with central tumours produced a slight but significant improvement in $\mathrm{FEV}_{1}$, while patients treated with mustine showed a slight decline.

Comparison of Mustine and Prednisolone in Respect of Decline in FEV 1 after Start of Irradiation.-The comparison was complicated by the compounding of drug and irradiation effects.

TABLE III-Group Average FEV 1 before Treatment with Prednisolone or Mustine Compared with Average FEV 1 during Drug Treatment but before Irradiation

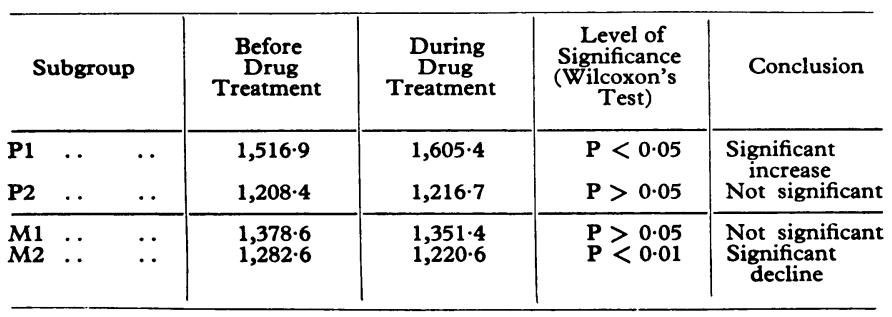

Two separate analyses were therefore made, each using an "index of decline" for purposes of comparison (Table II; Figs. 1 and 2). The first was:

1st index of decline $\left(I_{1}\right)=\frac{\text { mean } \text { FEV }_{1} \text { before any treatment }-X}{\text { pooled S.D. of group before treatment }}$

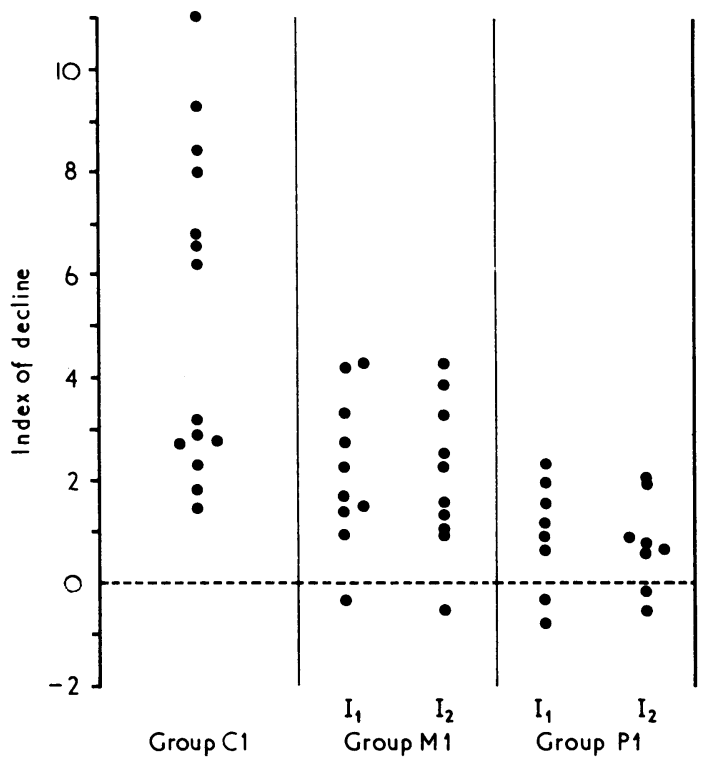

FIG. 1-Individual indices of decline in patients with central bronchial tumours (Subgroups 1 ).

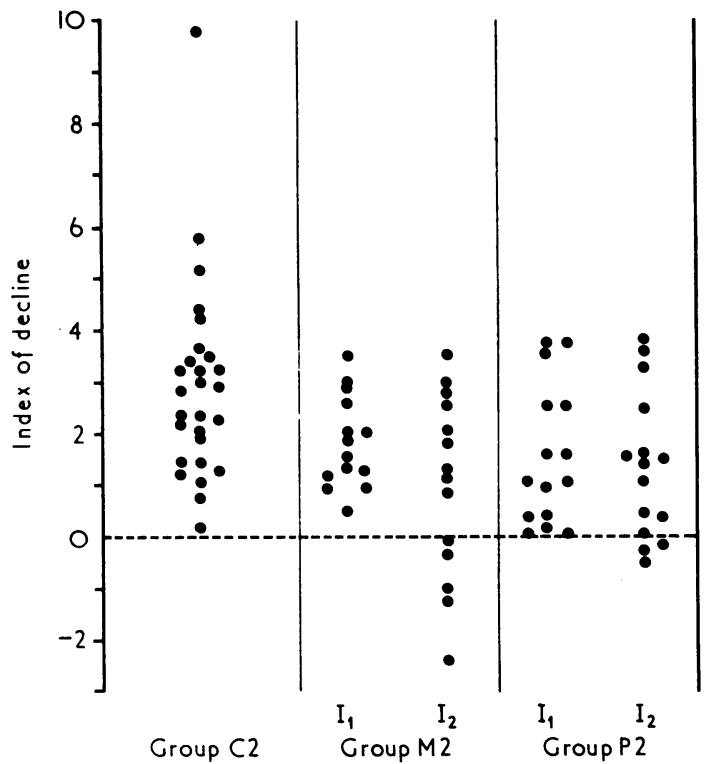

FIG. 2-Individual indices of decline in patients with lobar bronchial tumours (Subgroups 2). 
TABLE IV-Comparison of Combined Prednisolone and Mustine Subgroups with Control Subgroups, using Indices of Decline

\begin{tabular}{|c|c|c|c|c|c|c|c|c|}
\hline \multicolumn{4}{|c|}{ Subgroup } & Sample Size & Average $I_{1}$ & Level of Significance & Average $I_{2}$ & Level of Significance \\
\hline $\begin{array}{l}\mathrm{P} 1 \text { and } \mathrm{M} 1 \\
\mathrm{Cl}\end{array}$ & 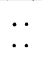 & $\begin{array}{l}\ldots \\
\cdots\end{array}$ & $\begin{array}{l}. \\
\cdots\end{array}$ & $\begin{array}{l}18 \\
14\end{array}$ & $\begin{array}{c}1.51 \\
5 \cdot 21 \\
\text { difference }=3.70\end{array}$ & $P<0.01$ & $\begin{array}{c}1.37 \\
5 \cdot 21 \\
\text { difference }=3.84\end{array}$ & $P<0.01$ \\
\hline $\begin{array}{l}\mathrm{P} 2 \text { and } \mathrm{M2} \\
\mathrm{C} 2 \mathrm{~N}\end{array}$ & 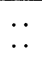 & 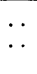 & $\begin{array}{l}\ldots \\
\ldots\end{array}$ & $\begin{array}{l}29 \\
27\end{array}$ & $\begin{array}{c}1.65 \\
2.94 \\
\text { difference }=1.29\end{array}$ & $P<0.05$ & $\begin{array}{c}1 \cdot 18 \\
2.94 \\
\text { difference }=1.76\end{array}$ & $P<0.05$ \\
\hline
\end{tabular}

where $\mathrm{X}=$ mean of lowest two $\mathrm{FEV}_{1}$ readings within the 10 which followed the start of drug treatment (this included some readings after irradiation). There was no significant difference in the value of $I_{1}$ in any of the treatment comparisons: (a) mustine group, comparing $\mathrm{M} 1$ and $\mathrm{M} 2 ;(b)$ prednisolone group, comparing $\mathrm{P} 1$ and $\mathrm{P} 2$; and (c) an overall analysis of variance on the four subgroups. The same conclusions were drawn when the second index of decline was used:

$$
\text { 2nd index of decline }\left(\mathrm{I}_{2}\right)=\frac{\text { average } \mathrm{FEV}_{1} \text { before any treatment }-\mathrm{Y}}{\text { pooled S.D. of group before treatment }}
$$

where $\mathrm{Y}=$ mean of lowest two $\mathrm{FEV}_{1}$ readings within the 10 which followed the start of irradiation (this excluded any readings before irradiation). While no significant difference was shown between the four subgroups who received preliminary drug treatment, the indices of decline were slightly greater in patients receiving mustine than in those treated with prednisolone.

Comparison of Combined Mustine and Prednisolone Pretreatment Groups with Control Group.-The numbers in each subgroup receiving prednisolone or mustine were small, and since there was no significant difference between these subgroups they were combined for comparison with the control patients. When indices of decline were used, the control group registered a greater fall in $\mathrm{FEV}_{1}$ during irradiation than did the combined mustine and prednisolone groups (Table IV), and these differences were significant at the $1 \%$ level when patients with central tumours (Subgroups 1) were compared.

Validity of $F E V_{1}$ as an Index of Airway Obstruction.-In order to establish whether a decline in $\mathrm{FEV}_{1}$ represented a true reduction in bronchial air flow, or merely reflected a general reduction in vital capacity during the early stages of treatment, a study of the changes in $\mathrm{FEV}_{1} / \mathrm{FVC}$ ratio (usually regarded as a reliable index of airway obstruction) was undertaken. The difference between mean pretreatment $\mathrm{FEV}_{1} / \mathrm{FVC}$ and the mean of the lowest $\mathrm{FEV}_{1} / \mathrm{FVC}$ during the first week of irradiation was calculated (denoted by $\mathrm{D}$ ). The value of $\mathrm{D}$ in Subgroups $\mathrm{C} 1, \mathrm{C} 2, \mathrm{M} 1, \mathrm{M} 2, \mathrm{P} 1$, and $\mathrm{P} 2$ was tested, and the differences between $C 1$ and $C 2, M 1$ and $M 2, P 1$ and $P 2, M 1$ and $P 1$, and $M 2$ and P2 were found not to be significant, but when $\mathrm{M} 1$ or $\mathrm{P} 1$ was compared with $\mathrm{C} 1$, and $\mathrm{M} 2$ or $\mathrm{P} 2$ with $\mathrm{C} 2$, significant differences were observed $(P<0.05)$. Since these statistical conclusions corresponded with those drawn from indices of decline based on $\mathrm{FEV}_{1}$, it was assumed that the latter accurately reflected changes in the degree of airway obstruction.

\section{Discussion}

Most of the previous physiological studies on the effects of deep $x$ rays in bronchial carcinoma have been concerned with disturbances of function caused by damage to the lung parenchyma (Whitfield et al., 1956; Deeley, 1960; Evans, 1960; Emirgil and Heinemann, 1961; Hoffbrand et al., 1965), and little attention has been paid to the effects of irradiation on the tumour itself. As has been shown by Cameron et al. (1969), these effects occur during the first 48 hours of treatment and are not delayed for several weeks, as in the case of irradiation damage to lung tissue. When a bronchial carcinoma is irradiated there is an initial phase of tumour swelling, which increases the degree of bronchial obstruction. If the tumour is situated in the region of the tracheal bifurcation the airway may become almost completely obstructed, and death from asphyxia may result.

It has been shown in the study reported in this paper that preliminary treatment with either intravenous mustine or oral prednisolone can prevent initial tumour swelling during irradiation. Prednisolone is marginally superior to mustine in this respect because it produces a slight, but significant, immediate increase in $\mathrm{FEV}_{1}$ which is not reversed by subsequent irradiation. A similar improvement is not observed with mustine, which has the additional disadvantage of being much more toxic and difficult to administer.

It is concluded that all patients with tumours involving the trachea or major bronchi who are being treated with deep $x$ rays should be protected from the risks of initial tumour swelling by preliminary treatment with prednisolone by mouth in a dose of $20 \mathrm{mg} /$ day for 24 hours before and 48 hours after the start of irradiation. Such treatment given for only 72 hours is unlikely to accelerate tumour growth and may prevent unnecessary fatalities.

We thank the staff of the Radiotherapy Unit, Western General Hospital, for their help in the investigation; Mr. W. Lutz for statistical advice; the Department of Medical Photography for the figures; and Miss Barbara MacMillan for secretarial help.

\section{References}

Cameron, S. J., Grant, I. W. B., Lutz, W., and Pearson, J. G. (1969). Clinical Radiology, 20, 12.

Deeley, T. J. (1960). Clinical Radiology, 11, 33.

Emirgil, C., and Heinemann, H. O. (1961). Fournal of Applied Physiology, 16, 331 .

Evans, J. C. (1960). Radiology, 74, 104.

Hoffbrand, B. I., Gillam, P. M. S., and Heaf, P. J. D. (1965). Thorax, 20, 303.

Whitfield, A. G. W., Bond, W. H., and Arnott, W. M. (1956). Quarterly fournal of Medicine, 25, 67. 